\title{
Investigation of the Sense Responsibility and Lifestyles of Sport-Scientific Faculty Students
}

\author{
Fatih Mehmet Ugurlu \\ Correspondence: Fatih Mehmet Ugurlu, Firat University School of Sport Sciences Elazıg, Turkey.
}

Received: October 9, 2017

doi:10.11114/jets.v5i12.2793

\author{
Accepted: November 4, $2017 \quad$ Online Published: November 13, 2017 \\ URL: https://doi.org/10.11114/jets.v5i12.2793
}

\begin{abstract}
This study was conducted to determine the levels of perception of aphasia (alexithymia) and loneliness in university students. The model of the research is descriptive and cross-sectional. It was held between February 1 and May 31, 2017. Survey form was used as data collection tool in the research. The questionnaire consists of personal information consisting of 8 questions, Toronto Alexithymia (TAS) scale consisting of 26 questions and UCLA loneliness scale consisting of 20 questions. The Toronto Alexithymia scale (TAS) scale is a self-reported scale consisting of 26 questions and 4 subscales to scale the alexithymic characteristics of individuals. The scale was developed by Taylar and Bagby (1988), first used by Dereboy (1990) in the expertise thesis and adapted to Turkish by Varol (1998). Scale sub-dimensions and Cronbach's Alpha coefficients obtained in this study are given respectively. 0.752 for the imagination, 0,752 for the constraint sub-dimension in the case of dreams, 0,761 for the sub-dimension of difficulty in distinguishing and recognizing feelings and physical senses, 0,718 for the sub-dimension of recognizing, recognizing and talking about emotion, and cognitive structure sub- was found to be 0.784 . The scale was developed by Russell and colleagues and reorganized by Russell et al. (1980). The Turkish reliability and validity study of the scale was conducted by Yaparel (1984). The scale is one-dimensional. In this study, Cronbach's Alpha coefficient for the UCLA scale was 0,782. The universe of the research is constituted by students from the Department of Teaching, Coaching Department, Management Department and Recreation Department of the Faculty of Sports Sciences of Firat University in 2016-2017. The sample of the research consists of 350 students who are educated in these sections. A simple coincidental voluntary sampling method was used in the selection of the sample. In the reliability of the sample, sample size calculation formula prepared by Yazıcioglu and Erdogan (2004) was used. The data were analyzed in the SPSS 16 packet program. In the analysis of the data, descriptive statistics, $t$ test, anova test and correlation analysis were used.
\end{abstract}

Keywords: deafness, loneliness, perception

\section{Introduction}

The fact that a person is a social being requires communication with other people. In this process, people have to adhere to logical facts as well as emotional events. In particular, the influence of emotions in interpersonal interaction is important in terms of establishing health relations. Emotional well-being is becoming evident when individuals cannot understand and perceive their own and others' feelings. Emotional well-being is becoming evident when individuals cannot understand and perceive their own and others' feelings. While this may not be a compliance problem because social relations are generally based on logical elements, it may cause some problems when it comes to private and personal relationships. Loneliness refers to a situation different from that of individuals alone. Loneliness is generally confronted as a feeling that individuals feel isolated and thus cause suffering. From this standpoint, loneliness can cause individuals to abstract themselves from their surroundings and society. Movement of solitude to advanced dimensions causes psychological and physical problems to occur in people.

\subsection{The Concept of Emotion Deafness}

The concept of deafness was first described in 1972 by Sifneos in the literature. Deafness is also expressed by the concept of alexithymia. In the past, this concept has been addressed in terms of disclosure of the symptoms of psychosomatic diseases, but now it is also considered as a personal qualification. (Sasioglu, Gülol, ve Tosun, 2014). The concept of alexithymia emerges as a concept derived from the Greek language. From a semantic point of view, the limitation of the person's mental functions, the inability of the person to understand the emotions, the acceptance of the emotions, and the inability of the person to find the words to explain the emotions (Taylor, \& Bagby, 2000). The 
feelings are part of the main qualities that make people human. In the sight of someone who has not seen a long time, the moment is seen as a feeling of immortality in a film that has touching qualities (Lüzumlu, 2013). The feeling of well-being, alexithymia, refers to the inadequacy of living in the imagination related to the emotional state of any one, in the formation of visual images, the matching of ideas and feelings. Some people cannot remember why they are aggressive when they are aggressive. Nevertheless, some people cannot remember the pleasant moment related to the event if they remember an event that makes them happy. Individuals with emotional well-being can be found in actions, can walk ideas, remember emotions, but have problems in interacting with feelings and thoughts. This situation causes individuals to have problems with themselves and their surroundings (Taylor, 2000) it is expressed that the deafness of the emotion generally appears in the sense of verbal and nonverbal perceptions in the emotional stimuli. The fact that the causes of emotional wellbeing cannot be determined is very difficult, which has led to the establishment of relevant opinions. One of these views is that genetic factors cause emotional distress, while others express that traumatic events are the cause of emotional distress (Y1ldiz, 2013). In a different view, socio-cultural factors also cause emotional deafness (Bagci, 2008). Individuals with emotionally deafness exhibit some personality traits. These personality traits are covered under four headings. These headings can be expressed as follows. (Parker, Taylor, \& Bagby, 2001).

1. Perceptions of emotion and meaning are strong,

2. The limitations of dreaming and dreaming,

3. The tendency to think operationally and at work,

4. Mental structure towards outward-adaptation.

Individuals with emotional distress who have difficulty in understanding emotions with difficulty have difficulty expressing their feelings when they are asked to express their feelings. Individuals with this problem generally choose to express their feelings through factors such as physical discomfort, relaxation, and relaxation (Mattila, Salminen, Nummi, \& Joukamaa, 2006). They behave as if they do not understand what they are feeling when asked. If their feelings are persistently asked, they talk about their thoughts and ideas instead of their feelings. Instead of telling them how they feel they are related to a situation or an event they do not desire, they describe their behavior and the event that takes place (Aygen, 2011). Individuals with emotional well-being cannot imagine and at the same time consider imagining being a waste of time. However, the imagination of these individuals is also very weak (Aygen, 2011). The imagination that is established together with the emotional ones cannot express emotionally and intensely the item that they want to imagine, but they are within the constraints of reality. The low level of imagination skills in individuals with emotional well-being cause the creativity skills to be low. However, these individuals are rarely able to remember their dreams (Bagc1, 2008). Although those who are emotionally charged tend to think operationally, they are in harmony with their surroundings even if they do not fully understand their emotions (Mattila, Salminen, Nummi, \& Joukamaa, 2006). In this respect, these individuals tend to reach a solution by focusing on short solutions instead of dealing with events in detail. This leads to an extremely mechanical life of these individuals (Bagc1, 2008). Because of the characteristics they possess, these individuals are referred to as compatible individuals (Parker, Taylor, \& Bagby, 2001). Individuals with emotional well-being are generally considered outward-looking individuals. They can interact seamlessly with their surroundings because of their exhibitions of attitude towards harmony and benefit. This causes them to focus on external stimuli from their internal stimuli in relation to their surroundings (Yalcin, 2010).

\subsection{Loneliness}

Loneliness occurs in different levels in each individual. However, the concepts of being alone and loneliness are separate from each other. Loneliness is not desirable because it causes people to feel pain. But for some people loneliness is a choice. Some artists can create their great works when they are alone (Cacioppo, et. 2010). Loneliness is often expressed as a condition that arises as a result of fear that is not related to someone who may interact in the environment or in the future in the context of the person's circumstances. It is also stated that the development of communication technologies is gradually increasing loneliness. It is said that the reason for this is the adoption of the urban lifestyle that emerges with modern life. It is becoming more difficult to address the basic needs of individuals from the urban lifestyle, such as belonging, cooperation, love, and understanding, acceptance (Cacioppo, J. T., Hughes, M. E., Waite, L. J., Hawkley, L. C., \& Thisted, R. A.2006). When the situations causing loneliness are evaluated, it is seen that many factors influence loneliness. Relevant to this alone is an evaluation; negative cognitive experiences, a negative experience, a weak social relationship, a lack of friends to share, and a low ability to establish and maintain a relationship (Alpass, \& Neville, 2003). It would be erroneous to think that the people around them are not alone. In some cases, individuals may feel loneliness with other people. The inability of the person to form special ties with other people can cause the person to feel loneliness to put walls on their relationship with others. It is expressed that there are three species alone. These can be expressed as follows (Derdiyok, 2015): 
a. Temporary loneliness: The type of loneliness that lasts for at least two hours. This causes the symptoms to be mild.

b. Situational loneliness: An important situation or event that an individual is experiencing is revealed. As a result of this, physical and mental disorders can occur in the person. Problems such as headache sleep disorders, anxiety and depression can occur.

c. Chronic loneliness: This type of loneliness can last for two years or more. This process does not follow a uniform traumatic event.

The feeling of loneliness is expressed in the following effects in individuals (Brehm, Kassin, \& Fein, 2002)

- Self-esteem is falling.

- They evaluate the others in negative form.

- There is an expectation that others evaluate them negatively.

- They do not trust their own thoughts.

- They are shy.

- They are insensitive to social situations and events.

- Avoid contact with the opposite sex.

In a study related to the classification of loneliness, loneliness was considered under five dimensions (Yahyaoglu, 2007). These;

1. Social status loneliness: The person is beginning to feel isolated from the environment he is in. In this case, people are increasingly alienated from collecting. These individuals do not want to be involved in the activities of the community.

2. Deep loneliness: The kind of loneliness that affects all people around the person. In this type of loneliness, the person finds signs of depression. It is a type of painful loneliness. The progression of depression causes the individual not to enjoy life. Conditions such as fatigue, fatigue, helplessness, and lack of decision are obvious. The individual is beginning to think about suicide.

3. Emotional loneliness: One feels loneliness because he can not get a response to his inner desires. The individual feels loneliness when he does not see his values, wishes, expectations, and the things he thinks he deserves. This loneliness can solve the individual or turn it into a chronic and self-destructive dimension.

4. Hidden loneliness: It seems that there is no problem when the person is evaluated from the outside. This kind of loneliness comes after the sadness and resentment that one has experienced. This sadness that has been experienced has not been exported. If this kind of loneliness is not looked at from a different window it is possible to turn into deep loneliness.

5. Triad loneliness: This type of loneliness is accompanied by fear and depression. From this point of view, individuals in this kind of loneliness have complex feelings. It is a mood that is contained in situations of rapid rage or depression.

\section{Method}

The model of the research is descriptive and cross-sectional. Survey form was used as data collection tool in the research. The questionnaire consists of personal information consisting of 8 questions, Toronto Alexithymia (TAS) scale consisting of 26 questions and UCLA loneliness scale consisting of 20 questions.

The Toronto Alexithymia scale (TAS) scale is a self-reported scale consisting of 26 questions and 4 subscales to scale the alexithymic characteristics of individuals. The scale was developed by Taylar and Bagby (1988), used for the first time by Dereboy (1990) in the specialty thesis, and adapted to Turkish by Varol (1998).

Scale sub-dimensions and Cronbach's Alpha coefficients obtained in this study are given respectively. 0.752 for the imagination, 0,752 for the constraint sub-dimension in the case of dreams, 0,761 for the sub-dimension of difficulty in distinguishing and recognizing feelings and physical senses, 0,718 for the sub-dimension of recognizing, recognizing and speaking power, cognitive structure sub- was found to be 0.784 .

UCLA (University of California, Los Angeles) is a measure of loneliness, a measure of 20 questions aimed at determining the level and level of loneliness of individuals. Scale Russell et al. (1978) and Russell et al. (1980) and the final version was given. The Turkish reliability and validity study of the scale was conducted by Yaparel (1984). The scale is one-dimensional. In this study, Cronbach's Alpha coefficient for the UCLA scale was 0,782. 
The student's universe constitutes the students who study at the Department of Teaching, Coaching Department, Management Department and Recreation Department at Firat University Sports Sciences Faculty. The sample of the research consists of 350 students who are educated in these sections. A simple random sample method was used in the selection of the sample. In the reliability of the sample, sample size calculation formula prepared by Yazıcioglu and Erdogan (2004) was utilized. The data were analyzed in the SPSS 16 packet program. In the analysis of the data, descriptive statistics, $t$ test, Anova test and correlation analysis were used.

\section{Findings}

Table 1. Findings Related to Demographic Characteristics

\begin{tabular}{|c|c|c|}
\hline & Frekans & $\%$ \\
\hline \multicolumn{3}{|l|}{ Section } \\
\hline Department of physical education and sport teacher & 100 & 28,6 \\
\hline Department of Coaching Education & 100 & 28,6 \\
\hline Sports Management Department & 100 & 28,6 \\
\hline Recreation Department & 50 & 14,3 \\
\hline Total & 350 & 100,0 \\
\hline \multicolumn{3}{|l|}{ Class } \\
\hline 1 & 100 & 28,6 \\
\hline 2 & 100 & 28,6 \\
\hline 3 & 75 & 21,4 \\
\hline 4 & 75 & 21,4 \\
\hline Total & 350 & 100,0 \\
\hline \multicolumn{3}{|l|}{ Gender } \\
\hline Girl & 169 & 48,3 \\
\hline Male & 181 & 51,7 \\
\hline Total & 350 & 100,0 \\
\hline \multicolumn{3}{|l|}{ Internet and Computer Usage in Everyday Life } \\
\hline $25 \%$ and below & 57 & 16,3 \\
\hline $26-50 \%$ & 98 & 28,0 \\
\hline $51-75 \%$ & 108 & 30,9 \\
\hline $75 \%$ and above & 87 & 24,9 \\
\hline Total & 350 & 100,0 \\
\hline \multicolumn{3}{|l|}{ Emotional Draw Situation } \\
\hline Yes & 200 & 57,1 \\
\hline No & 150 & 42,9 \\
\hline Total & 350 & 100,0 \\
\hline \multicolumn{3}{|l|}{ Mother-Father's Situation } \\
\hline They Live Together & 242 & 69,1 \\
\hline They Live Separately & 60 & 17,1 \\
\hline they divorced & 46 & 13,1 \\
\hline Other & 2 & 0,6 \\
\hline Total & 350 & 100,0 \\
\hline \multicolumn{3}{|l|}{ Hand Use } \\
\hline Left & 110 & 31,4 \\
\hline Right & 240 & 68,6 \\
\hline Total & 350 & 100,0 \\
\hline \multicolumn{3}{|l|}{ Life Standard (Economic Level) } \\
\hline Low & 39 & 11,1 \\
\hline Middle & 216 & 61,7 \\
\hline High & 95 & 27,1 \\
\hline Total & 350 & 100,0 \\
\hline
\end{tabular}

$51.7 \%$ of the respondents were male and $48 \%$ were female. $30,9 \%$ of the students who participated in the research spend $51-75 \%$ of their daily life using internet and computer, $57,1 \%$ have emotional well-being, $69,1 \%$ of the parents live together, $68,6 \%$ and $61.7 \%$ have a moderate life standard. 
Table 2. Relationship between Personal Information and Emotional Deafness

\begin{tabular}{|c|c|c|c|c|}
\hline & \multicolumn{4}{|l|}{ TAÖ } \\
\hline & Fac_1 & Fac_2 & Fac_3 & Fac_4 \\
\hline \multicolumn{5}{|l|}{ Section } \\
\hline $\begin{array}{l}\text { Department of physical education and sport } \\
\text { teacher }\end{array}$ & 17,61 & 29,97 & 14,37 & 13,75 \\
\hline Department of Coaching Education & 17,01 & 29,37 & 14,94 & 13,81 \\
\hline Sports Management Department & 18,63 & 29,61 & 14,38 & 14,24 \\
\hline Recreation Department & 17,44 & 29,06 & 15,62 & 13,52 \\
\hline $\mathrm{F}$ & 5,347 & 0,924 & 2,944 & 0,566 \\
\hline $\mathrm{p}$ & $\mathbf{0 , 0 0 1}$ & 0,429 & $\mathbf{0 , 0 3 3}$ & 0,638 \\
\hline \multicolumn{5}{|l|}{ Class } \\
\hline 1 & 17,44 & 29,03 & 14,92 & 13,23 \\
\hline 2 & 17,91 & 29,52 & 15,53 & 15,01 \\
\hline 3 & 17,65 & 29,81 & 14,44 & 13,84 \\
\hline 4 & 17,84 & 30,09 & 14,22 & 13,25 \\
\hline $\mathrm{F}$ & 0,475 & 1,529 & 4,948 & 5,449 \\
\hline $\mathrm{p}$ & 0,700 & 0,207 & $\mathbf{0 , 0 0 2}$ & 0,001 \\
\hline \multicolumn{5}{|l|}{ Gender } \\
\hline Girl & 17,82 & 29,62 & 14,71 & 13,76 \\
\hline Male & 17,59 & 29,51 & 14,96 & 13,97 \\
\hline $\mathrm{t}$ & 0,705 & 0,284 & 0,924 & 0,533 \\
\hline $\mathrm{p}$ & 0,481 & 0,777 & 0,356 & 0,357 \\
\hline \multicolumn{5}{|c|}{ Internet and Computer Usage in Everyday Life } \\
\hline $25 \%$ and below & 18,14 & 29,50 & 14,82 & 13,96 \\
\hline $26-50 \%$ & 17,71 & 29,41 & 14,88 & 14,03 \\
\hline $51-75 \%$ & 17,39 & 29,55 & 14,63 & 13,60 \\
\hline $75 \%$ and above & 17,79 & 29,79 & 15,05 & 13,97 \\
\hline $\mathrm{F}$ & 0,806 & 0,195 & 0,469 & 0,308 \\
\hline $\mathrm{p}$ & 0,491 & 0,900 & 0,704 & 0,819 \\
\hline \multicolumn{5}{|l|}{ Emotional Draw Situation } \\
\hline Yes & 17,77 & 29,42 & 14,86 & 14,12 \\
\hline No & 17,62 & 29,75 & 14,82 & 13,54 \\
\hline $\mathrm{t}$ & 0,464 & 0,895 & 0,149 & 1,494 \\
\hline $\mathrm{p}$ & 0,643 & 0,371 & 0,882 & 0,136 \\
\hline \multicolumn{5}{|l|}{ Mother-Father's Situation } \\
\hline They Live Together & 17,67 & 29,89 & 14,61 & 13,77 \\
\hline They Live Separately & 18,11 & 28,61 & 15,46 & 14,25 \\
\hline They divorced & 17,41 & 29,13 & 15,23 & 13,97 \\
\hline Other & 16,00 & 28,00 & 14,50 & 12,00 \\
\hline $\mathrm{F}$ & 0,749 & 2,685 & 2,370 & 0,479 \\
\hline $\mathrm{p}$ & 0,523 & 0,047 & 0,070 & 0,697 \\
\hline \multicolumn{5}{|l|}{ Hand Use } \\
\hline Left & 18,00 & 29,53 & 15,26 & 14,40 \\
\hline Right & 17,56 & 29,58 & 14,65 & 13,62 \\
\hline $\mathrm{t}$ & 1,286 & 0,129 & 2,158 & 1,910 \\
\hline $\mathrm{p}$ & 0,199 & 0,898 & $\mathbf{0 , 0 3 2}$ & 0,057 \\
\hline \multicolumn{5}{|l|}{ Life Standard (Economic Level) } \\
\hline Low & 17,58 & 28,87 & 15,58 & 14,92 \\
\hline Middle & 17,75 & 29,56 & 14,68 & 13,99 \\
\hline High & 17,64 & 29,86 & 14,89 & 13,17 \\
\hline $\mathrm{F}$ & 0,079 & 1,142 & 2,238 & 3,676 \\
\hline $\mathrm{p}$ & 0,924 & 0,320 & 0,108 & $\mathbf{0 , 0 2 6}$ \\
\hline
\end{tabular}

* Subjected to parametric tests (t-Test and Anova) as a result of the Kolmogorov-Smirnov test.

Fac_1: Imagination, constraint in dreaming

Fac_2: Difficulty in distinguishing and recognizing feelings and physical senses

Fac_3: Strength of recognizing feelings, recognizing and spelling 
Fac_4: Outward-centered, cognitive structure for adaptation

When the relationship between personal information and emotional deafness was examined, it was determined that there was a statistically significant relationship between the sub-dimensions of imagination, awareness of limitations and feelings in dreaming, recognition and verbal abstinence subdivisions $(\mathrm{p}<0,05)$.

According to the Tukey test from Post Hoc tests to determine which variance is caused by variance, the sense of limitation in the dreaming experience in the sport management department students and the sense of recognizing, recognizing and saying emotions are higher in recreation department students than in the other departments.

In Table 2, it was determined that there was a statistically significant relationship between feelings of empathy, recognition and verbal abstinence and cognitive structure subscales with external centering and compliance ( $\mathrm{p}<0,05)$.

According to the Tukey test from the post hoc test to determine which variance is originating differently, according to the Tukey test, the students with the second grade are more likely to recognize emotions, to recognize and to express emotions, and to have an externally centered cognitive structure perception.

In Table 2, it was determined that there was a statistically significant relationship between the difficulty in distinguishing and recognizing emotions and physical sensations and the status of parents ( $p<0,05)$. According to the Tukey test of Post Hoc tests conducted to determine which variance is caused by variance, the perceptions of parents and children living with their parents and those with divorce and difficulties in distinguishing and recognizing feelings and physical senses are higher than others.

In Table 2, it was determined that there was a statistically significant relationship between the sense of empathy, recognition and verbal abstinence sub-dimension and hand use status $(\mathrm{p}<0,05)$. Left-handers' perceptions of empathy, recognition, and spoken empathy are greater than those using their right hand.

In Table 2, it was determined that there was a statistically significant relationship between the external centered cognitive structure subscale for compliance and the life expectancy status $(\mathrm{p}<0,05)$.

According to the Tukey test, the individuals with low economic status are less likely to be external-centered and have a cognitive structure perception of adaptation than the others, in order to determine which variance is sourced from different sources. 
Table 3. Relationship between Personal Information and Perception of Loneliness

\begin{tabular}{|c|c|c|c|}
\hline \multirow[b]{2}{*}{ Section } & \multicolumn{3}{|l|}{ UCLA } \\
\hline & Average & $\mathbf{F}$ & $\mathbf{p}$ \\
\hline $\begin{array}{l}\text { Department of physical education and sport } \\
\text { teacher }\end{array}$ & 55,22 & \multirow{4}{*}{10,976} & \multirow{4}{*}{$\mathbf{0 , 0 0 0}$} \\
\hline Department of Coaching Education & 58,49 & & \\
\hline Sports Management Department & 56,16 & & \\
\hline Recreation Department & 60,54 & & \\
\hline Class & Average & $\mathbf{F}$ & $\mathbf{p}$ \\
\hline 1 & 57,59 & \multirow{4}{*}{11,524} & \multirow{4}{*}{$\mathbf{0 , 0 0 0}$} \\
\hline 2 & 59,58 & & \\
\hline 3 & 53,36 & & \\
\hline 4 & 54,26 & & \\
\hline Gender & Average & $\mathbf{t}$ & $\mathbf{p}$ \\
\hline Girl & 56,65 & \multirow{2}{*}{1,499} & \multirow{2}{*}{0,135} \\
\hline Male & 57,67 & & \\
\hline $\begin{array}{l}\text { Internet and Computer Usage in } \\
\text { Everyday Life }\end{array}$ & Average & $\mathbf{F}$ & $\mathbf{p}$ \\
\hline $25 \%$ and below & 59,89 & \multirow{4}{*}{0,184} & \multirow{4}{*}{0,907} \\
\hline $26-50 \%$ & 57,40 & & \\
\hline $51-75 \%$ & 56,92 & & \\
\hline $75 \%$ and above & 57,43 & & \\
\hline Emotional Draw Situation & Average & $\mathbf{t}$ & $\mathbf{p}$ \\
\hline Yes & 57,42 & \multirow{2}{*}{0,823} & \multirow{2}{*}{0,411} \\
\hline No & 56,86 & & \\
\hline Mother-Father's Situation & Average & $\mathbf{F}$ & $\mathbf{p}$ \\
\hline They Live Together & 56,50 & \multirow{4}{*}{3,510} & \multirow{4}{*}{$\mathbf{0 , 0 1 6}$} \\
\hline They Live Separately & 58,25 & & \\
\hline They divorced & 59,15 & & \\
\hline Other & 62,50 & & \\
\hline Hand Use & Average & $\mathbf{t}$ & $\mathbf{p}$ \\
\hline Left & 58,70 & \multirow{2}{*}{3,060} & \multirow{2}{*}{$\mathbf{0 , 0 0 2}$} \\
\hline Right & 56,48 & & \\
\hline Life Standard (Economic Level) & Average & $\mathbf{F}$ & $\mathbf{p}$ \\
\hline Low & 58,43 & \multirow{3}{*}{3,589} & \multirow{3}{*}{$\mathbf{0 , 0 2 9}$} \\
\hline Middle & 56,47 & & \\
\hline High & 58,28 & & \\
\hline
\end{tabular}

* Subjected to parametric tests (t-Test and Anova) as a result of the Kolmogorov-Smirnov test.

In Table 3, loneliness perception was examined according to personal information. A statistically significant relationship was found between loneliness perception and department, class, parental status, hand use and life standards (p <0,05).

According to the Tukey test results from the Post Hoc tests to determine the variance, the students who are recreation department students, the students who read 2nd class, the parents whose parents are divorced, the other students who give the other answers about the status of parents and the students whose life standarts are middle level are lonely. The study also found that the left handed students had higher levels of loneliness than the right handed students.

Table 4. Relationship between TAS and UCLA

\begin{tabular}{llllll}
\hline & \multicolumn{7}{c}{ TAÖ } & & \\
\hline UCLA & & Fac_1 & Fac_2 & Fac_3 & Fac_4 \\
& $\mathbf{r}$ &,- 015 &, 134 &, 636 &, 229 \\
& $\mathbf{p}$ &, 787 &, 012 &, 000 &, 000 \\
& $\mathbf{n}$ & 350 & 350 & 350 & 350 \\
\hline
\end{tabular}

Fac_1: Imagination, constraint in dreaming

Fac_2: Difficulty in distinguishing and recognizing feelings and physical senses

Fac_3: Strength of recognizing feelings, recognizing and spelling

Fac_4: Outward-centered, cognitive structure for adaptation 
When the relationship between emotional deafness and loneliness was examined, it was found that there was a statistically significant relationship between the sense of loneliness and the difficulty in recognizing and recognizing emotions and somatic senses, the perception of emotions, the recognition of emotions, <0.05); There is no statistically significant relationship between the sense of restriction and loneliness in dreaming, dreaming ( $>0,05)$.

The difficulty in distinguishing and recognizing emotions and physical senses, the difficulty in recognizing, recognizing and speaking emotions, and the relationship between perceptions of loneliness and external cen- tralized cognitive structure perceptions are positive.

The higher the perception of emotions, the recognition of emotions, the difficulty in recognizing and recognizing emotions and physical senses, the greater the perception of emotion, the greater the perception of cognition, the more externally centered and adaptive cognition, the higher the perceptions of loneliness.

\section{Discussion and Conclusion}

The relationship between emotional deafness and loneliness perception was investigated on the students who were studying sports. There was a statistically significant relationship between three sub factors of emotional well-being and loneliness in the study. The difficulty in recognizing and recognizing emotions and physical senses, the difficulty in recognizing feelings, recognizing and speaking, and the relationship between perceptions of cognition and externalization, cognitive structure and loneliness were found positively. Loneliness perceptions of students who had difficulties in describing and expressing feelings and physical sensations and who had problems of adaptation to the outside world were found to be higher.

Kocak (2003) found a significant relationship between the alexithymia and loneliness levels of students in the study of university students in terms of the relationship between alexithymia and loneliness in terms of some variables. Ozdemir and Güres (2010) investigated the level of alexithymia and loneliness in the orienting athletes in terms of various variables, and it was determined that the alexithymia level of Orientring athletes had a moderate, positive and significant relationship between their levels of alexithymia. The sense of imagination in the research, the sense of limitation in the dreaming situation, the sense of awareness, recognition and spoken emotion in the students of the department of sports administration are higher in recreation department students than in the other departments; According to the students in the second grade, students with second grade had higher perception of emotions, recognition and speaking difficulty, and externally centered cognitive structure perceptions of adaptation; mother and father living together, and parents' divorce, feelings and physical senses are more likely to distinguish and recognize than others; the cognitive structure perception towards the external center of the individuals with low economic level was found to be lower than the others. Cooper and Halmstrom (1984) reported that the alexithymic features of women were seen more often than males in their studies of relationship between alexithymia and somatic complaints. In the study, it was also found that the students who were recreation department students, those who read 2nd class, the parents whose parents were divorced and gave other answers about the status of parents, the loneliness levels of the students with middle school life and the students who use the left hand were higher than the students using the right hand. Unal (2005) stated that the alexithymia personality traits of college students are only effective in life span. However, Kilinc and Sevinc (2005) found that loneliness levels of adolescents did not differ according to sex.

\section{References}

Alpass, F. M., \& Neville, S. (2003). Loneliness, Health and Depression in Older Males, Aging \& Mental Health, 7(3), 212-216. https://doi.org/10.1080/1360786031000101193

Aygen, S. (2011). Prediction of Alexithymic Level In Mothers Of Children And Adolescents With Autism, Master Thesis. T. C. Maltepe University Institute of Social Sciences Psychology Department Clinical Psychology Program, Istanbul.

Bagci, T. (2008). Examination of the level of alexithymia of university students according to some variables, M.Sc. Thesis. T. C. Gazi University, Institute of Educational Sciences, Department of Educational Sciences, Department of Guidance and Psychological Counseling, Ankara, Turkey.

Brehm, S. S., Kassin, S. M., \& Fein, S. (2002). Social Psychology, 5 ed. Houghin Mifflin Company, Boston.

Cacioppo, J. T., Hawkley, L. C., Crawford, L. E., Ernst, J. M., Burleson, M. H., Kowalewski, R. B., ... Berntson, G. G. (2002). Loneliness and Health: Potential Mechanisms, Psychosomatic Medicine, 64(3), 407-417. https://doi.org/10.1097/00006842-200205000-00005

Cacioppo, J. T., Hughes, M. E., Waite, L. J., Hawkley, L. C., \& Thisted, R. A. (2006). Loneliness as a Specific Risk Factor for Depressive Symptoms: Cross-Sectional and Longitudinal Analyses, Psychology and Aging, 21(1), 140. https://doi.org/10.1037/0882-7974.21.1.140 
Derdiyok E. B. (2015). The Relationship between Loneliness Levels and Alcohol Consumption of University Students, Master Thesis, Institute of Social Sciences, Beykent University, Istanbul.

Dereboy, İ. F. (1990). A Study on the Psychometric Properties of Alestimatic Self - Efficacy Scales, Expertise Thesis, Hacettepe University, Institute of Health Sciences, Ankara, Turkey.

Kılınc, H., \& Sevim, S. (2005). Loneliness and Cognitive Distortions in Ergenes, Journal of Educational Sciences, University, 38(2), 67-99.

Kocak, R. (2003). A comparison of alexithymia and loneliness in university students in terms of some variables and the relationship between them. Journal of Turkish Psychological Counseling and Guidance, 2(19), 15-24.

Lüzumlu, U. (2013). Examination of different university students according to the levels of alexithymia of stress coping styles, M.Sc. Thesis. T. C. Mersin University Educational Sciences Institute Educational Sciences Department of Counseling and Psychological Counseling Department, Mersin.

Mattila, A. K., Salminen, J. K., Nummi, T., \& Joukamaa, M. (2006). Age is strongly associated with alexithymia in the general population, Journal of psychosomatic research, 61(5), 629-635. https://doi.org/10.1016/j.jpsychores.2006.04.013

Ozdemir, N. G. (2010). Investigation of alexithymia and loneliness in Oriental athletes in terms of various variables. 11 th International Sport Sciences Congress, 872-874, Antalya.

Parker, J. D., Taylor, G. J., \& Bagby, R. M. (2001). The relationship between emotional intelligence and alexithymia. Personality and Individual differences, 30(1), 107-115. https://doi.org/10.1016/S0191-8869(00)00014-3

Russell, D., Peplau, L. A., \& Cutrona, C. E. (1980). The revised UCLA Loneliness Scale: Concurrent and discriminant validity evidence. Journal of personality and social psychology, 39(3), 472-480, 1980. https://doi.org/10.1037/0022-3514.39.3.472

Russell, D., Peplau, L. A., \& Ferguson, M. L. (1978). Developing a measure of loneliness. Journal of Personality Assessment, 42, 290-294. https://doi.org/10.1207/s15327752jpa4203_11

Sasioglu, M., Gülol, Ç., \& Tosun, A. (2014). Alexithymia: treatment initiatives, Psychiatric Current Approaches, 6(1), 22-31.

Taylar, G. J., \& Bagby, R. M. (1988). Creation Validity of the Toronto "Alexithymia Scale", Psychosomatic Medicine, 50, 500-509. https://doi.org/10.1097/00006842-198809000-00006

Taylor, G. J. (2000). Recent developments in alexithymia theory and research, The Canadian Journal of Psychiatry, 45(2), 134-142. https://doi.org/10.1177/070674370004500203

Taylor, G. J., \& Bagby, R. M. (2000). An overview of the alexithymia construct.

Unal, G. (2005). Assessment of Respect for Alexithymia and Self-Esteem in a Group of University Students, 40. National Congress of Psychiatry.

Varol, S. (1998). The Effect of Group Psychological Counselor on the Alexithymic Characteristics of University Students, Doctoral Thesis, and Ondokuz May University, Institute of Social Sciences, Samsun.

Yahyaoglu, R. (2007). Psychology of Absence: From Kurt Kapan to Huzur Port: Nesil Publications, Istanbul.

Yalcin, S. B. (2010). Examination of the students' emotions according to their alexithymia and psychological needs, Doctoral Thesis. T. C. Selcuk University Educational Sciences Institute Educational Sciences Department of Psychological Counseling and Guidance Science Department, Konya.

Yaparel, R. (1984). Connection between Perception of Loneliness and Perception of Causes of Success and Failure in Social Relations, Unpublished Master's Thesis, Hacettepe University, Institute of Social Sciences, Ankara.

Yazıcıoglu, Y., \& Erdogan, S. (2004). SPSS applied scientific research methods. Ankara: Detail Publishing.

Yıldız, B. (2013). The relationship between the importance given to material values in children and alexithymia, Master Thesis. T. C. Sakarya University Institute of Educational Sciences Educational Sciences Department of Psychological Services in Education Department of Science, Sakarya.

\section{Copyrights}

Copyright for this article is retained by the author(s), with first publication rights granted to the journal.

This is an open-access article distributed under the terms and conditions of the Creative Commons Attribution license which permits unrestricted use, distribution, and reproduction in any medium, provided the original work is properly cited. 